\title{
A pesquisa-formação sob diferentes perspectivas no campo do desenvolvimento profissional docente
}

\author{
Priscilla de Andrade Silva Ximenes ${ }^{1}$ \\ Luciana Guimarães Pedro ${ }^{2}$ \\ Avani Maria de Campos Corrêa ${ }^{3}$
}

\begin{abstract}
RESUMO
O objetivo desse artigo é discutir diferentes tipologias da pesquisaformação, que se manifesta com características e peculiaridades na forma de pesquisa-ação, pesquisa colaborativa e pesquisa-ação críticocolaborativa à luz de um referencial teórico crítico. Essas pesquisas em educação, especialmente no campo da formação de professores, têm em comum o compromisso com a transformação e ancoram-se na perspectiva contra hegemônica de formação e de produção do conhecimento científico. Para tanto, o trabalho foi organizado em duas partes: na primeira, procuramos encontrar elementos e considerações de ordem teóricometodológicas sobre as especificidades, potencialidades e principais desafios da pesquisa-formação. $\mathrm{Na}$ segunda parte, apresentamos o percurso teórico-metodológico, análises e resultados de uma pesquisa colaborativa realizada com professores da Educação básica da Rede pública de Ensino de Uberlândia/MG (PEDRO, 2019) com o intuito de analisar questões relacionadas ao uso dessa metodologia de pesquisa, tendo em vista o fortalecimento da pesquisa-formação em educação e o desenvolvimento profissional docente.
\end{abstract}

PALAVRAS-CHAVE: Pesquisa-formação. Pesquisa ação. Pesquisa colaborativa. Formação docente. Desenvolvimento Profissional Docente.

\footnotetext{
${ }^{1}$ Doutora em Educação. Professora adjunta na Faculdade de Educação da Universidade Federal de Catalão - UFCAT, Catalão, Goiás, Brasil. Orcid: https://orcid.org/0000-0002-0683-6285. E-mail: priteducadora@ hotmail.com.

${ }^{2}$ Pós doutorado em Educação. Doutora em Educação. Escola Parque Tibetano, Carmo da Cachoeira, Minas Gerais, Brasil. Orcid: https://orcid.org/0000-0002-0806-8814. E-mail: lucianaguimarãespedro@ gmail.com.

${ }^{3}$ Doutoranda na Universidade Federal de Uberlândia, Uberlândia, Minas Gerais, Brasil. Orcid: https://orcid.org/00000001-5962-0536. E-mail: avanimariacorrea@gmail.com.
} 
Training research from different perspectives in the field of professional teacher development

\begin{abstract}
This article aims to discuss different types of training research, which manifests itself with characteristics and peculiarities in the form of action research, collaborative research and critical-collaborative action research in the light of a critical theoretical framework. These researches in education, especially in the field of teacher education, share a commitment to transformation and are anchored in the counterhegemonic perspective of training and scientific knowledge production. Therefore, the work was organized in two parts: in the first, we tried to find elements and theoretical-methodological considerations about the specificities, potentials, and main challenges of training research. In the second part, we present the theoretical-methodological path, results and analysis of a collaborative research carried out teachers who work in Basic School in municipal and state public schools in Uberlândia/MG (PEDRO, 2019) and its surroundings, with the aim of analyze issues related to the use of this research methodology, as well as the main assumptions to be observed for the strengthening of training research in education, especially in the field teacher professional development.
\end{abstract}

KEYWORDS: Research-training. Action research. Collaborative research. Teacher training. Teacher Professional Development.

\title{
Investigación en formación desde diferentes perspectivas en el campo del desarrollo profesional del profesorado
}

\section{RESUMEN}

El objetivo de este artículo es discutir diferentes tipologías de investigación-formación, manifestada con características y peculiaridades en la forma de investigación-acción crítico-colaborativa a la luz de un referencial teórico crítico. Estas investigaciones en educación, especialmente en el campo de formación de profesores, tienen en común el compromiso con la transformación anclándose en la perspectiva contra hegemónica de formación y de producción de conocimiento científico. Para eso, el trabajo fue organizado en dos partes: en la primera, procuramos elementos y consideraciones de orden teórico-metodológicas 
sobe las especifidades, potencialidades y principales desafíos de la investigación-formación. En la segunda parte, presentamos la ruta teórico-metodológica, análisis y resultados de una investigación colaborativa realizada con profesores de Educación Básica de la Red Pública de Enseñanza de Uberlândia/MG (PEDRO, 2019) con la intención de analizar cuestiones relacionadas al uso de esta metodología de investigación, teniendo en vista el fortalecimiento profesional docente.

PALABRAS CLAVE: Investigación-formación. Investigación-acción. Investigación colaborativa. Formación docente. Desarrollo Profesional Docente.

$$
* * *
$$

\section{Introdução}

A formação de professores/as no Brasil, suas especificidades, dilemas e desafios constituem-se foco de preocupação e interesse de pesquisadores/as do mundo inteiro, seja do ponto de vista das políticas públicas, das práticas pedagógicas, dos saberes e identidade profissional, da profissionalização e trabalho docente, dentre outros temas. Tal interesse pode ser constatado pelo crescente número de produções científicas, eventos e publicações especificamente dedicados à temática; pela visibilidade alcançada na mídia e pela crescente parceria entre escolas e universidades, em se tratando da formação inicial e continuada de professores.

No que tange a consolidação dessa temática como campo de estudos, André (2010, p. 178) pontua que "um indicador adicional da constituição da área é a insistente atenção dos políticos, administradores e investigadores à formação de professores como peça-chave da qualidade do sistema educativo", justificando talvez o grande interesse como área temática de pesquisa. O fato é que a formação de professores e seus desdobramentos se apresentam em uma extensa produção científica, na maior parte das vezes sendo configuradas como o cerne da qualidade do ensino-aprendizagem. 
Contudo, apesar da quantidade de produções e do crescente interesse pela temática, ainda são inúmeros os desafios e razões que explicam um descompasso entre o que se oferece na formação de professores e as exigências cotidianas do trabalho escolar. Dentre as muitas contradições engendradas a esse fenômeno educacional, ressaltase a centralidade dada à formação dos professores que atuam na Educação Básica pelo atual modelo de regulação das políticas educativas nacionais, circunscrito no ciclo de reformas nos sistemas educacionais de países da América Latina a partir dos anos de 1990.

Dentre outras contradições, no que se refere aos impactos das reformas sobre a formação docente, ressaltamos que no atual cenário educacional as concepções que delineiam a formação de professores são pautadas sobre o alicerce das noções de competência, eficiência, competitividade e produtividade. Isso torna-se visível quando observamos a tentativa de padronização do currículo e do trabalho docente sob a lógica do capital, das políticas neoliberais e da ordenação do Estado mínimo. O mesmo se dá quando consideramos o engendramento da educação e da formação de professores a um ideário determinado pelo mercado a partir dos princípios administrativos e empresariais: gestão, planejamento, previsão, avaliações sistêmicas, controle e êxito, materializados pela implementação de documentos oficiais de caráter normativo/prescritivo, como é o caso da BNCC (BRASIL, 2017) e da BNC Formação de professores (BRASIL,2019).

Evidencia-se nesse campo de contradições das políticas educacionais dois projetos em disputa, especialmente, no que se refere à formação de professores. De um lado a defesa por concepções progressistas, críticoemancipadoras e, de outro lado o fortalecimento e a manutenção de concepções conservadoras de educação.

Nesse contexto paradoxal das reformas, destacam-se pesquisas e relatórios da educação brasileira, com o intuito da obtenção de evidências científicas para apontar (des)caminhos para (con)formação de professores, marcados por investimentos de organismos internacionais e pela 
precarização/ desqualificação do trabalho docente sob uma lógica gerencialista de educação. Do outro lado, são realizadas inúmeras pesquisas em educação, especialmente no campo da formação de professores, que têm em comum o compromisso com a transformação social, ancoradas na perspectiva contra hegemônica de formação e produção do conhecimento.

Dentre essas pesquisas, destacamos a de Pedro (2019), cujo o percurso teórico-metodológico será apresentado nas partes subsequentes desse texto, a de Jordão (2016), Melo e Naves (2014), Silva e Bueno (2021), dentre outras, as quais têm apontado para uma tendência de superação do modelo da racionalidade técnica, subsidiado pela premissa pragmática e tecnocrata de educação e de formação docente, segundo o qual um profissional competente/eficiente é aquele capaz de solucionar problemas, através da aplicação rigorosa de teorias e procedimentos científicos.

Ressaltamos, ainda, as pesquisas realizadas, no âmbito do Grupo de Estudos e Pesquisas sobre Docência na Educação Básica e Superior (GEPDEBS), vinculado ao Programa de Pós-Graduação em Educação da Universidade Federal de Uberlândia (UFU). Desde 2015, quando foi constituído, o grupo tem como eixo as relações entre a formação docente, os saberes e as práticas, buscando compreender os processos pelos quais os professores da Educação básica e/ou Ensino Superior constroem seus saberes e como a formação inicial e continuada repercutem nas ações educativas e na constituição de suas identidades profissionais. Além disso, o grupo tem se destacado na proposição de pesquisas-formação realizadas por docentes e discentes, que se manifestam com características e peculiaridades na forma de pesquisa-ação, pesquisa colaborativa e pesquisa-ação crítico-colaborativa à luz de um referencial teórico crítico (MELO, 2018).

Esses estudos têm apontado que a pesquisa-formação, vem sendo utilizada de diversas formas e intencionalidades, com vistas a formação e emancipação dos sujeitos, em que a produção do conhecimento está subjacente elaboração e reflexão contínua da práxis pedagógica, ancoradas na unidade teoria-prática. Dentre os fundamentos 
apresentados, defende-se que ao se realizar pesquisas com professores, é importante considerá-los como sujeitos-autores do seu próprio processo formativo, diminuindo a hierarquização entre pesquisadores e participantes da pesquisa e contribuindo para a reflexão críticacolaborativa sobre a sua prática docente, bem como os limites e possibilidades dos diversos condicionantes engendrados no seu trabalho.

No entanto, a literatura nos apresenta várias definições para o processo de pesquisa- formação, visto que se trata de um termo polissêmico. A pluralidade quanto a nomenclatura e ao seu significado social e, ainda, da configuração que ela assume no âmbito das pesquisas sobre formação docente, possivelmente esteja atrelada às especificidades históricas e epistemológicas desse tipo de pesquisa, bem como aos diferentes contextos em que ela tem sido utilizada. Embora tenham aspectos comuns, apresentam-se com terminologias, definições, conceitos e fundamentos filosóficos distintos, tornando árdua e complexa a tarefa de aprofundar na sua compreensão e definição.

Dessa forma, tendo como referência os diferentes enfoques, formas e percursos teórico-metodológicos, atribuídos a esse tipo de pesquisa, bem como seu potencial formativo, propomos o presente trabalho com o intuito de discutir e analisar diferentes tipologias da pesquisa-formação, que se manifesta com características e peculiaridades na forma de pesquisa colaborativa, pesquisa-ação e pesquisa-ação críticocolaborativa, à luz de um referencial teórico crítico. Para tanto, o trabalho foi organizado em duas partes: na primeira, procuramos encontrar elementos e considerações de ordem teórico-metodológicas sobre as especificidades, singularidades, potencialidades e principais desafios da pesquisa-ação, pesquisa colaborativa e pesquisa-ação críticocolaborativa. Nos baseamos em autores que influenciaram fortemente a conceituação e propagação da pesquisa-formação no Brasil, como: Ibiapina (2008), Franco (2005) e Pimenta (2005). 
$\mathrm{Na}$ segunda parte, apresentamos o percurso teórico-metodológico, análises e resultados de uma pesquisa colaborativa realizada com professores licenciados que atuam no Ensino Fundamental II e Ensino Médio de escolas públicas municipais e estaduais de Uberlândia (MG) e seus arredores, com o intuito de analisar questões relacionadas ao uso dessa metodologia de pesquisa, bem como apresentar os principais pressupostos a serem observados para o fortalecimento da pesquisa-formação na educação, especialmente no campo da formação de professores.

\section{Epistemologia da Pesquisa-formação: diferentes enfoques}

Tendo em vista o compromisso com a transformação da sociedade por meio da produção de conhecimento científico crítico no campo da educação e do desenvolvimento profissional docente, aprofundaremos nas questões que envolvem a epistemologia da Pesquisa-formação, dando ênfase na pesquisaação, na pesquisa colaborativa e na pesquisa-ação crítico-colaborativa.

A escolha por esse enfoque, justifica-se na medida em que pesquisas como a de Magalhães e Souza (2012) apontam que apesar de um significativo e gradativo aumento no número de pesquisas e publicações sobre a formação e a atuação do professor, ainda é muito comum que se façam pesquisas sobre os professores tomando-os como os grandes responsáveis pelos sucessos e fracassos no processo de ensino-aprendizagem, não analisando a profissão docente considerando as diferentes forças que a determina.

A definição dos professores(as) como problema é, atualmente, um tema que está presente tanto entre os que defendem sua reformulação, no sentido de modificar a atuação dos(as) professores(as) para adaptá-la às novas exigências do capital, quanto entre aqueles que são contra essas adaptações, uma vez que se preocupam não só com a quantidade, mas também e, sobretudo, com a qualidade dessa atuação (MAGALHÃES; SOUZA, 2012, p. 670).

As autoras enfatizam o quanto essa concepção de professor corrobora para sustentar a visão hegemônica de educação em nossa 
sociedade e, subsidiadas por Sacristán (2006, p. 82), estabelecem uma análise crítica desta produção, considerando que, embora a profissão docente esteja em pauta, a maior parte das investigações realizadas "[...] é enviesada, parcial, desestruturada, descontextualizada e não entra na essência dos problemas" da docência.

Partindo desse pressuposto, defendemos que ao se realizar pesquisas sobre formação de professores, é importante considerar os professores como sujeitos-autores do seu próprio processo formativo, diminuindo a hierarquização entre pesquisador e sujeitos da pesquisa e contribuindo para a reflexão sobre a sua prática docente e sobre o seu processo de desenvolvimento profissional, bem como os limites e possibilidades do seu trabalho.

Esse viés que conduz para o desenvolvimento de pesquisas de modo colaborativo vai ao encontro do método Materialista Histórico Dialético, que foi a perspectiva teórica que fundamentou esse trabalho. Segundo esse método, em uma pesquisa científica, o fenômeno deve ser analisado em seu processo, de maneira dialética, ao invés de se tomar como base o objeto em si; o objetivo da pesquisa não deve ser descrever o fenômeno, mas explicá-lo em seu movimento, em sua historicidade, estabelecendo uma relação entre os vários fatores que o determinam; e, por fim, a análise deve partir do concreto real para as relações mais básicas que determinam tal fenômeno, compreendendo-o em sua essência histórica (VIGOTSKI, 2000).

A escolha por um referencial epistemológico crítico, relaciona-se com a concepção de que a produção de conhecimento está interligada a partir de três movimentos simultâneos: de crítica, de construção do novo conhecimento e de ação com vistas à transformação, tendo como eixo norteador as categorias marxistas: trabalho, mediação e transformação (MARX, 2004). Nesse sentido, transformação da realidade implica em movimento, em mudança, e não apenas limitar-se à análise crítica. Assim, é de suma importância a coerência entre método e metodologias 
de estudos, pois a partir da aproximação com o materialismo históricodialético compreendemos a realidade vivenciada pelos professores como um todo, uma totalidade articulada, em que cabe ao pesquisador e participantes de pesquisa transformá-la e não apenas criticá-la.

Baseando em Desgagné (2007) e Pimenta (2015) compreendemos a necessidade de fortalecer as metodologias de pesquisa voltadas à formação de professores que visem a diminuição do distanciamento existente entre o mundo do exercício profissional e o da pesquisa. A partir de tal afirmativa, destacamos as pesquisas participativas, colaborativas, de intervenção e/ou pesquisa-formação como possibilidade de unidade entre pesquisa e formação, na medida em que compreende os docentes como protagonistas do seu processo de desenvolvimento e como sujeitos que podem construir conhecimento sobre o ensinar por meio da reflexão crítica sobre sua atividade, na dimensão coletiva.

Considerando isso, na primeira parte desse trabalho realizamos o estado da questão ${ }^{4}$ sobre os conceitos e discussões considerando três tipos de pesquisa, subsidiadas pelas seguintes obras: "Pesquisa colaborativa: investigação, formação e produção de conhecimento" (IBIAPINA, 2008) e os artigos "Pedagogia da Pesquisa-Ação" (FRANCO, 2005) e "Pesquisa-ação crítico-colaborativa: construindo seu significado a partir de experiências com a formação docente" (PIMENTA, 2005).

Dessarte, o estado da questão possibilitará conhecer e refletir criticamente acerca das metodologias de pesquisas referidas e seus impactos na área de formação de professores/as, retomando dimensões históricas, políticas e culturais. Portanto, nosso objetivo não é apenas apresentar os conceitos de cada tipo de pesquisa, mas amparadas no materialismo histórico-dialético, pretendemos conhecer a historicidade, interrelacionamento com a área de formação de professores e a visão de totalidade de cada metodologia de pesquisa.

\footnotetext{
${ }^{4}$ Para Terrien (2014, p.2) a finalidade do estado da questão é de "levar o pesquisador a registrar, a partir de um rigoroso levantamento bibliográfico, como se encontra o tema ou o objeto de sua investigação no estado atual da ciência ao seu alcance. "
} 


\title{
A pesquisa colaborativa em educação segundo Ibiapina
}

Para Ibiapina (2008), desenvolver uma investigação colaborativa em educação requer o envolvimento de pesquisadores e professores no processo de coprodução de conhecimentos para a pesquisa e no desenvolvimento profissional dos pares por meio de uma postura colaborativa cujo intuito é criar espaço de estudo, reflexão e construção de novos saberes e possibilidades de ação frente aos desafios educacionais.

Essa metodologia de pesquisa surge na educação como uma possibilidade importante para o desenvolvimento de pesquisas do tipo emancipatórias que têm como marcas: a horizontalidade nas relações entre os colaboradores, o movimento dialético entre teoria e prática e a reflexão crítica acerca dos aspectos que envolvem o campo de atuação dos docentes, considerando sempre o contexto sociopolítico que engendra a realidade microssocial (IBIAPINA, 2008).

Assim, nessa modalidade investigativa é importante estar a todo o momento atento à relação que há entre a educação e a sociedade, uma vez que,

\begin{abstract}
Parte-se do princípio de que, para transformar a escola, é preciso compreender que educação e sociedade são fenômenos complexos e contraditórios e que a escola, além de instrumento de transmissão dos saberes acumulados e de formação de mão-obra qualificada, é também espaço de transformação. Isso significa reconhecer que os conflitos existentes na escola fazem parte dos condicionantes sociais que impõem limites às práticas docentes, mas também saber visualizar as possibilidades de transformação dessa realidade (IBIAPINA, 2008, p. 27).
\end{abstract}

Outro aspecto importante para considerarmos quando nos referimos a esta modalidade de pesquisa é a compreensão acerca do próprio termo colaborativa. O que colaborar quer dizer nesse contexto? Para Ibiapina (2008 p. 34) "colaborar significa tomada de decisões democráticas, ação comum e comunicação entre investigadores e agentes sociais". Isto não indica, necessariamente, que professores e pesquisador devam participar juntos de 
todas as etapas da pesquisa, ter tarefas iguais e dedicarem-se na mesma intensidade. Na verdade, quando falamos em pesquisa colaborativa, falamos objetivamente em todos os partícipes terem voz e vez no processo de coprodução de conhecimentos sobre e para a educação, visando compreender as condições concretas do trabalho docente.

Logo, na pesquisa colaborativa o pesquisador oferece sua contribuição não apenas quando redige um trabalho acadêmico, mas sobretudo, quando constrói condições para que o grupo reflita de modo crítico sobre a complexidade das situações educativas considerando a dialogicidade entre teoria e prática. Os professores, por sua vez, colaboram na medida em que compartilham aspectos do seu cotidiano de trabalho, buscando compreender as relações conflituosas inerentes à docência no intuito de criar possibilidades de atuação, o que resulta em seu desenvolvimento profissional (IBIAPINA, 2008).

Portando, o desenvolvimento de um trabalho colaborativo pressupõe constituir um grupo de sujeitos que tenham interesses pessoais, profissionais e sociais comuns e que se disponha a refletir sobre um dado tema baseado no respeito mútuo e na qualificação do saber-fazer de cada sujeito envolvido, culminando em uma formação democrática, coletiva, reflexiva, crítica, politizada, dialógica e feita por e entre pares.

Para desenvolver uma investigação colaborativa no âmbito acadêmico, é necessário que o pesquisador adote posturas que, de fato, favoreçam à colaboração entre os pares. Inicialmente recomenda-se que o pesquisador compartilhe com os professores todos os detalhes do processo de pesquisa, estimulando-os a participarem ativamente de cada etapa vivenciada. Nesse sentido, é importante que reflitam coletivamente sobre o tema, o objeto de investigação, o objetivo, as concepções teóricas que norteiam o trabalho, a metodologia utilizada para construir o corpus de pesquisa, os caminhos escolhidos para fazer as análises das informações e a forma de divulgação dos resultados (IBIAPINA, 2008). 
$\mathrm{Na}$ sequência Ibiapina (2008) recomenda a sistematização de procedimentos essenciais para a concretização de pesquisas nessa modalidade. Para a autora o ciclo colaborativo da pesquisa em educação deve iniciar com a sensibilização dos colaboradores para os princípios da pesquisa colaborativa, por meio de conversas que esclareçam as características principais desta metodologia investigativa e com a negociação das atribuições do mediador (pesquisador) e dos colaboradores (professores), deixando claro o papel de cada um.

Além de dialogar com os colaboradores sobre tudo o que envolve o processo de pesquisa, Ibiapina (2008) ainda ressalta a importância de conversar minuciosamente sobre cada aspecto que envolve os encontros formativos: os objetivos dos encontros, a forma como serão organizados, o tipo de interação e envolvimento com a proposta, a necessidade de realização de leituras teóricas e de partilha das reflexões suscitadas, o período de duração dos encontros e da pesquisa e a necessidade ou não de anonimato.

Em seguida deve-se realizar o levantamento das necessidades formativas e dos conhecimentos prévios dos envolvidos na pesquisa. Esse ponto é fundamental, pois é a partir do conhecimento das temáticas que os professores desejam apreender, das dificuldades encontradas no cotidiano de atuação, das lacunas percebidas em sua formação inicial, de suas experiências profissionais e de suas aspirações que poderão ser definidas as leituras e o modo como os encontros serão conduzidos. Tendo sempre em mente a organização de um espaço em que os docentes possam construir "conhecimentos, habilidades e atitudes capazes de proporcionar-lhes condições de compreensão das situações problemáticas vivenciadas, bem como de resolução e mudança dos contextos de atuação" (IBIAPINA, 2008, p. 42).

Assim, de acordo com a autora compreende-se que para pesquisar colaborativamente, é necessário que pesquisadores e professores se reúnam constantemente para refletir sobre esses conhecimentos, a partir de ciclos reflexivos que auxiliem a análise, o dialogismo e a colaboração entre pares 
de diferentes níveis de competência profissional, ampliando os níveis de conhecimento teórico e prático dos pesquisadores e dos professores.

O cenário da pesquisa colaborativa é, por conseguinte, marcado pela coprodução de conhecimentos entre os docentes, na medida em que professores e pesquisador elaboram os conhecimentos que possuem e suas experiências profissionais para compartilhar com os demais, mediados pela fala do outro e por leituras teóricas, eles ampliam suas possibilidades de compreensão sobre a docência e constroem novas formas de pensar e atuar como educador.

Nesse processo de reconstrução, as significações sociais e pessoais elaboradas ultrapassam o espaço de compreensão do texto em si, uma vez que "penetraram no sistema conceitual já elaborado pelo docente, fazendo-o evoluir para outro nível". Na reflexividade, "o professor mergulha na prática e traz à tona a teoria para compreender de forma mais clara os conceitos que guiam a atividade docente" reconstruindo, de forma crítica e reflexiva, sua práxis pedagógica . (IBIAPINA, 2008, p. 47).

Para estruturar esse processo de reflexividade na pesquisa colaborativa, Ibiapina (2008), inspirada nos escritos de Freire (2004) e Smyth (1992), propõe a organização das ações reflexivas com base nos seguintes passos: a descrição, a informação, a confrontação e a reconstrução. De modo sintético, o primeiro momento refere-se à descrição detalhada da prática profissional; o segundo caracteriza as reflexões que voltam-se para o entendimento dos fundamentos que norteiam as escolhas feitas pelos professores no exercício de sua profissão; o terceiro momento, o de confrontação é um período crucial nesse processo de reflexão, pois é quando os professores buscam compreender de modo crítico o significado social de suas ações, ponderando acerca da manutenção ou transformação das desigualdades, diferenças e preconceitos e, por fim, no momento final, temse a possibilidade de reconstruir a prática profissional.

A objetivação desse processo reflexivo pode ser feita, segundo a autora, por intermédio de diferentes ferramentas, recursos e procedimentos que são utilizados como dispositivos mediadores no desenvolvimento da 
investigação. Como por exemplo: diálogo face a face; videoformação; narrativa autobiográficas; observação colaborativa e/ou sessões reflexivas.

\section{A pesquisa ação na formação docente em Franco (2005) e Pimenta (2005): a Pedagogia da Pesquisa-ação e a Pesquisa-ação crítico-colaborativa}

Para explicitar sua perspectiva sobre a pedagogia da pesquisa-ação, Franco (2005) aprofunda reflexões sobre a pertinência e as possibilidades da pesquisa-ação como instrumento pedagógico e científico, nos permitindo refletir sobre as possibilidades e limites da pesquisa. A partir de Kurt Lewin (1946) a autora relata um pouco do histórico da pesquisa-ação e destaca em que contexto e intencionalidades a pesquisa-ação tem sido utilizada nas últimas décadas, bem como seus diferentes aspectos metodológicos. Desse modo, afirma a necessidade do aprofundamento sobre sua essencialidade epistemológica, e suas possibilidades como práxis investigativa para garantir a unidade teoria e método e a validade científica dos estudos realizados.

A partir de um levantamento de pesquisas realizadas com essa metodologia, observando a direção, sentido e encaminhamentos metodológicos, a autora apresenta três conceituações diferentes com base em levantamentos e análises de trabalhos de pesquisa-ação no Brasil: a pesquisaação colaborativa, a pesquisa-ação crítica e a pesquisa-ação estratégica.

De acordo com Franco (2005), dentre as principais diferenças entre as concepções apresentadas está o fato de que na primeira a busca de transformação é solicitada pelo grupo de referência à equipe de pesquisadores, e cabe ao pesquisador cientificizar um processo de mudança anteriormente desencadeado pelos sujeitos do grupo; na pesquisa-ação crítica a necessidade de transformação é percebida a partir dos trabalhos iniciais do pesquisador com o grupo e tem como objetivo principal a emancipação do sujeito e por último a pesquisa-ação estratégica a transformação é previamente planejada, sem a participação dos sujeitos, e apenas o pesquisador acompanhará os efeitos e avaliará os resultados de sua aplicação. 
Nesse sentido a autora enfatiza que:

A condição para ser pesquisa-ação crítica é o mergulho na práxis do grupo social em estudo, do qual se extraem as perspectivas latentes, o oculto, o não familiar que sustentam as práticas, sendo as mudanças negociadas e geridas no coletivo. Nessa direção, as pesquisas-ação colaborativas, na maioria das vezes, assumem também o caráter de criticidade (FRANCO, 2005, p.486).

Subsidiada por autores como Lewin (1946), Kincheloe (1997), Barbier (2002) , Thiollent (2003), a autora traça um percurso histórico da pesquisaação para compreendermos as transformações epistemológicas presentes ao longo do tempo, mostrando como esse tipo de pesquisa se fortaleceu no espaço educacional, sobretudo no que tange ao caráter formativo aliado à pesquisa. A partir do levantamento histórico a autora aponta uma questão problema chave para compreender essa modalidade investigativa: qual o tipo de pesquisa pretendido quando nos referimos à pesquisa ação?

Na análise empreendida por Kincheloe (1997, p. 179), a pesquisa-ação crítica, “[...] não pretende apenas compreender ou descrever o mundo da prática, mas transformá-lo; (...) é sempre concebida em relação à prática existe para melhorar a prática." Dessa forma, o esforço dos pesquisadores críticos da ação é de tentar descobrir os aspectos da ordem social dominante que minam os esforços para se conseguir objetivos emancipatórios.

Com o intuito de fundamentar epistemologicamente esse tipo de pesquisa, Franco (2005) distingue as pistas encontradas em três dimensões: i)dimensão ontológica: referente à natureza do objeto a ser conhecido; ii) dimensão epistemológica: referente à relação sujeito-conhecimento; iii) dimensão metodológica: referente a processos de conhecimento utilizados pelo pesquisador.

Ao explicitar tais dimensões, a autora supracitada destaca qual a ação nos referimos na pesquisa-ação e ainda qual a função do pesquisador e dos participantes nesse tipo de pesquisa. Ressalta que para tal abordagem faz-se necessário o afastamento da perspectiva positivista para que possa haver a tão necessária interpenetração de papéis, em que pesquisador e 
participantes sejam co-autores da pesquisa, estabeleçam uma comunicação de igual para igual com os atores, dando-lhes voz, compartilhando poder e reconhecendo-lhes a capacidade de dar sentido aos acontecimentos. Tudo isso, sempre na perspectiva de colaborar com as mudanças pretendidas pelo grupo e sem perder a dimensão do caráter formativo do processo.

Corroborando com essa discussão, Pimenta (2005) traz uma abordagem do processo de reconfiguração do sentido e do significado da pesquisa-ação enquanto pesquisa crítico-colaborativa, tendo como referência duas experiências coordenadas por ela juntamente às equipes da Universidade de São Paulo e de escolas públicas do referido estado. Os pressupostos que sustentam a referida abordagem demonstram que cabe aos pesquisadores estabelecerem vínculos com os professores da escola a fim de se construir uma parceria com eles para ajudar a problematizar situações da prática. Sublinhase que, ao refletirem, os professores são capazes de analisar, problematizar e compreenderem a sua própria prática e é justamente neste movimento que Pimenta (2005) enfatiza a necessidade de se utilizar os saberes pedagógicos, científicos e da experiência, pois são constituintes da docência.

A autora assevera que o pressuposto mais profícuo de formação contínua,

[...] é aquela que toma os contextos escolares como objeto de análise, o que favorece a relação teoria e prática, uma vez que nas modalidades tradicionais de formação contínua, como cursos e treinamentos diversos, a mediação entre essas modalidades e os contextos escolares não têm sido estabelecidas, resultando num investimento mais na profissionalização do professor e menos na alteração das práticas institucionais necessárias à melhoria dos resultados da escolaridade (PIMENTA, 2005, p. 534).

Aprofundando esta questão a referida autora considera que a problemática da pesquisa está em detectar até que ponto uma pesquisa colaborativa pode favorecer processos de construção identitária grupal, beneficiando um espaço de reflexão a todos os envolvidos, buscando produzir conhecimentos cujo objetivo seja produzir mudanças na cultura institucional resultando na qualificação profissional. 
Ainda na concepção de Pimenta (2005) a pesquisa-ação colaborativa tem por intuito incentivar ações e práticas institucionais. No entanto, tornase crítica de acordo com o compromisso dos envolvidos diretamente na pesquisa, na medida em que possibilite a transformação das práticas institucionais e viabilize o papel de democratização social e política da sociedade. Em outras palavras, considera os atores sociais no processo, pois colaboram na formulação das conclusões "partilhando e contribuindo do conhecimento produzido, constituindo-se também eles pesquisadores e autores das mudanças" (PIMENTA, 2005, p. 529).

Pimenta (2005, p.534) valendo-se da colaboração de Franco (2004) reitera que "a condição para ser pesquisa-ação crítica é o mergulho na práxis do grupo social em estudo, de onde se extraem as perspectivas latentes, o oculto, o não familiar que sustentam as práticas, e as mudanças serão negociadas e geridas no coletivo". Acrescente-se que "as pesquisas-ação colaborativas, na maioria das vezes, assumem também o caráter de criticidade” (p.534).

Ao ampliar o sentido da referida pesquisa, esta autora confirma a relevância da realização dessa modalidade de pesquisa entre universidades e escolas. Nesse processo, é fundamental partir das necessidades dos professores envolvidos para determinar os objetivos de pesquisa. Conforme os professores vão constatando que estão aptos a refletir e a alterar suas práticas, se fortalecem enquanto profissionais.

Como realçou Pimenta (2005) é necessário tempo para se "implantar e amadurecer" para implementar mudanças significativas na docência, uma vez que é preciso persistência para se modificar o autoritarismo vigente. Para a autora, faz-se necessário fortalecer a profissionalidade dos professores, através de explicitação, registro, reflexão compartilhada, proposição, realização, acompanhamento e análise de projetos participativos que sejam subsidiados pelas necessidades formativas expressas pelos professores e/ou percebidas pelos pesquisadores. Com isso, "possibilitam o alargamento dos espaços de decisão e de autonomia dos professores frente às imposições que lhes são impingidas" (PIMENTA, 2005, p. 537). 
Quanto ao potencial da pesquisa-ação crítico colaborativa e da pedagogia da pesquisa ação na formação docente, as pesquisas realizadas no Brasil e no mundo ratificam as transformações das práticas proporcionadas pela referida abordagem. Há de se destacar também que tais resultados tornam férteis as transformações nas políticas públicas, especialmente nas formas de gestão dos sistemas de ensino e nas novas tessituras acerca da formação de professores e do desenvolvimento profissional docente.

\section{Um caminho possível - a pesquisa colaborativa e o desenvolvimento docente}

Finalizada a primeira parte do artigo em que trouxemos diferentes elementos referentes à epistemologia da pesquisa-formação sob diferentes enfoques, neste segundo momento trazemos como exemplo ilustrativo da pesquisa-formação na perspectiva colaborativa, o percurso teórico-metodológico, análises e resultados de uma investigação desenvolvida em nível de doutorado.

A referida pesquisa intitulada Como se fora brincadeira de roda - o grupo colaborativo como mediador do desenvolvimento docente (PEDRO, 2019), teve como temática o desenvolvimento profissional docente e objetivou apreender e analisar o processo de desenvolvimento profissional docente no movimento de um grupo colaborativo. Para isso, realizou, como proposta de formação contínua, um curso de extensão universitária voltado a professores licenciados, com até seis anos de experiência profissional, que atuavam no Ensino Fundamental II e Ensino Médio de escolas públicas municipais e estaduais de Uberlândia e seus arredores.

Para o desenvolvimento desta proposta formativa, tomou-se como subsídios: os conhecimentos da Educação que compreendem à docência como profissão; os princípios da Teoria Histórico-Cultural e seus conceitos; as discussões sobre o processo de escolarização promovidas pela Psicologia Escolar e Educacional numa vertente crítica e as 
orientações trazidas pela Pesquisa Colaborativa. Para o presente texto enfatizaremos os aspectos metodológicos desta investigação.

A ferramenta escolhida para proporcionar a construção do processo reflexivo junto aos professores colaboradores foi o desenvolvimento de sessões reflexivas que, consistiu em síntese, na realização de encontros com professores, organizados com o intuito de compartilhar significados e sentidos sobre um dado problema ou aspecto de sua prática profissional (IBIAPINA, 2008).

Foram desenvolvidas 16 sessões reflexivas que compuseram o curso de extensão. Este se constituiu na forma de um grupo colaborativo, conforme orientações de Ibiapina (2008), do qual foram colaboradores, 11 professores licenciados que atuavam no Ensino Fundamental II e Médio de escolas públicas de Uberlândia e região. Além disso, a investigação restringiu-se aos professores que se encontravam nos seis primeiros anos de atuação profissional, ou seja, nas fases de "exploração" e "estabilização" da carreira.

A fase de exploração, refere-se aos três primeiros anos de atuação profissional e é o momento em que o professor tem o contato inicial com a prática docente e busca sobreviver diante dos desafios apresentados. A fase de estabilização, por sua vez, vai dos quatro aos seis anos de experiência profissional e é o momento em que o docente define com mais clareza sua identidade profissional (GARCIA, 1999).

As sessões reflexivas foram apreendidas na íntegra por meio de audiogravação e foram, posteriormente, transcritas, transformando a palavra falada em texto. Para complementar o material empírico produzido, utilizou-se também as anotações da pesquisadora e dos professores feitas em diário de bordo, além dos materiais produzidos nos próprios encontros, tais como, desenhos, cartas, cartazes etc.

Considerando as orientações da pesquisa colaborativa, os cinco primeiros encontros foram dedicados a criação de vínculo entre os participantes, a organização dos aspectos práticos e ao levantamento das expectativas e necessidades dos professores. Assim, todos os detalhes do curso de extensão e, consequentemente, da pesquisa foram definidos em 
grupo. As temáticas foram escolhidas a partir das demandas apresentadas pelos próprios professores colaboradores e, em síntese, abordaram os seguintes pontos: a estrutura física da escola, espaço, material, tradicionalismo; a agressividade, indisciplina, desinteresse, relação professor-estudante; inclusão e atendimento educacional especializado; sexualidade, diversidade, preconceito, bullying; relacionamento com a direção, supervisão e colegas de trabalho, burocracia, falta de apoio e ser professor, remuneração, excesso de trabalho, formação contínua, autonomia, medos, saúde do trabalhador.

Para analisar o material empírico produzido pela pesquisa, optou-se pela metodologia dos Núcleos de Significação que orienta partir do empírico expresso na fala, nos gestos e demais elementos de comunicação registrados pelo pesquisador para, assim, compreender as zonas de sentido expressas pelos sujeitos de pesquisa (AGUIAR; OZELLA, 2006; NAVES, 2011).

Assim, considerando todo o corpus de pesquisa construído na referida investigação a análise foi feita seguindo os seguintes passos: leitura cuidadosa do material empírico produzido; elaboração dos préindicadores de análise, destacando os trechos mais significativos; agrupamento dos pré-indicadores, por complementaridade, similaridade ou contradição, criando indicadores iniciais de compreensão dos dados; construção de núcleos de significação, elaborados a partir da organização dos indicadores, de modo a identificar zonas de sentido que ajudem na compreensão dos fenômenos investigados e, por fim, foi feita a análise dos núcleos de significação, por meio do exercício de articulação entre eles, os contextos mais amplos que constituem a realidade investigada e o referencial teórico pertinente (AGUIAR; OZELLA, 2006; PEDRO, 2019) .

Tomando como problema a seguinte pergunta: Como ocorre o processo de desenvolvimento profissional docente no movimento de um grupo colaborativo?, feitas as devidas análises, a referida investigação culminou na compreensão de que o processo de desenvolvimento vivido no e pelo grupo, ocorreu por meio de três zonas de sentido principais: a mediação do outro, do 
meio, dos elementos estéticos e dos conhecimentos teóricos partilhados; o drama, a crise, a confrontação e experimentação do novo e a afetividade presente no modo como o grupo colaborativo foi construído e conduzido.

Ao analisar o material empírico produzido pela pesquisa, foi possível identificar que os indicadores de análise que traziam indícios de transformação nas crenças e concepções sobre a docência e de ressignificação dos saberes profissionais tinham em sua raiz a mediação como princípio básico. No referido grupo colaborativo a mediação se deu, especificamente, no âmbito da relação com o outro, com a pesquisadora como psicóloga escolar, com os elementos estéticos, com o meio e os textos da Psicologia Escolar e Educacional numa vertente crítica que subsidiaram as conversas realizadas. Nesse sentido, através das trocas e diálogos que aconteceram ao longo das sessões reflexivas, possível ver, no movimento do grupo colaborativo que os professores foram transformando suas crenças e concepções sobre a docência e ressignificando seus saberes profissionais, indicando como o espaço de formação contínua construído se configurou como uma situação social propícia ao desenvolvimento docente.

Consciente de que o homem é um ser social movido e que as suas necessidades formativas advem da sua prática social (a docência) foi possível observar ao longo dos encontros formativos, que as crises vivenciadas pelos professores os ajudavam a elaborar novos sentidos sobre a docência e, consequentemente, construir práticas pedagógicas diferenciadas, além de colaborar na constituição da sua identidade profissional.

Enfim, na pesquisa em questão, o grupo colaborativo evidenciou-se como uma situação social propícia ao desenvolvimento profissional do professor e isso não se deu naturalmente, mas sim por meio das escolhas específicas feitas pela pesquisadora.

A opção por seguir cuidadosamente as orientações da pesquisa colaborativa, considerando a horizontalidade nas relações, a tomada de decisão de forma democrática e a comunicação clara entre os colaboradores da pesquisa (IBIAPINA, 2008), logo, culminou em indícios 
de colaboração efetiva. Para isso, algumas ferramentas foram utilizadas: a busca por conhecer os participantes de modo mais aprofundado, compreendendo os aspectos profissionais e pessoais que determinam a sua constituição; a investigação dos conhecimentos prévios dos professor e suas necessidades formativas; a construção de um contrato em grupo com orientações sobre a forma de estar no grupo; o acolhimento dos participantes a cada encontro com um saboroso e cuidadoso lanche; a escrita de uma carta reflexiva sintetizando todo o processo vivido.

Assim, as decisões pedagógicas adotadas para a condução do grupo colaborativo evidenciaram a importância da afetividade nos espaços de aprendizagem, uma vez que, "[...] os processos afetivos complexificam-se durante o desenvolvimento, sofrem influência e influem nos processos cognitivos, mantendo com eles uma relação dialética durante toda a vida do sujeito (LEITE, 2017, p. 163).

O potencial do grupo colaborativo em questão se deu a partir da utilização de alguns pressupostos: o planejamento cuidadoso do curso de extensão tendo claro os referenciais teóricos utilizados para subsidiar as sessões reflexivas; o esclarecimento dos objetivos da pesquisa junto ao grupo; a construção de um contrato coletivo; a organização dos encontros fazendo uso de diferentes recursos didáticos; o estabelecimento de uma postura horizontal e democrática com todos; ter a afetividade como guia para orientar as relações entre os professores; propor uma escuta atenta e ativa; ter uma postura cuidadosa para com os detalhes da pesquisa; conduzir a pesquisa com sensibilidade e flexibilidade; reconhecer as próprias falhas como mediadora do grupo; utilizar a Arte como mediadora nos diálogos; considerar o contexto histórico, cultural e político no qual o grupo estava inserido; valorização dos aspectos pessoais e subjetivos dos colaboradores; fazer avaliações e dar feedback ao longo do processo e expressar, como mediadora, o amor pela docência e a educação.

Tudo isso repercutiu em transformações nos professores e em suas práticas pedagógicas, demonstrando que o movimento do grupo colaborativo 
foi fundante da dimensão formativa para a construção identitária, para a ressignificação dos saberes docentes e elaboração de novos saberes, portanto, para o desenvolvimento profissional dos professores

Além de evidenciar que o desenvolvimento profissional abrange também o desenvolvimento do professor como sujeito uno, singular e subjetivo que exerce uma profissão dotada de complexidade. Apontando, por fim para o valor da construção de coletivos de professores que possibilitem "transcender os caminhos solitários da docência, para encontros solidários, por meio da construção de parcerias colaborativas e fraternas voltadas à emancipação e transformação do humano, da educação e da sociedade" (PEDRO, 2019, p 182).

\section{Considerações finais}

Considerando que nos tempos atuais muitas medidas foram impostas à Educação no sentido de destituí-la do seu papel no processo de constituição e desenvolvimento de sujeitos conscientes, críticos e reflexivos, acreditamos que o investimento em propostas de formação contínua que promovam um espaço coletivo de partilha e construção de novos sentidos sobre a prática profissional dos professores, é fundamental. Considera-se que as distintas e importantes contribuições trazidas por Ibiapina (2008), Pimenta (2005) e Franco (2005), além do exposição do percurso teórico-metodológico de uma pesquisa colaborativa realizada com professores da Educação Básica, possibilitam-nos ter uma visão geral acerca das possibilidades de implementação e realização da pesquisa formação no campo da educação.

Ademais, percebemos que apesar das singularidades de cada metodologia, as epistemologias dessas pesquisas se aproximam na medida em que sugerem ações formativas numa perspectiva crítica e emancipatória que intervenham diretamente na práxis do professor e na transformação social. Nesse sentido, a pesquisa-formação a partir das perspectivas teóricometodológicas analisadas, se apresenta como possibilidade de transformação dos processos formativos tendo em vista o desenvolvimento profissional de 
docentes da educação básica e superior; e de produção do conhecimento científico numa perspectiva contra hegemônica, a partir da consolidação parcerias colaborativas (entre Universidade e escola) voltadas à emancipação e transformação do sujeito, da educação e da sociedade.

\section{Referências}

AGUIAR, W. M. J.; OZELLA, S. Núcleos de Significação como Instrumento para a Apreensão da Constituição dos Sentidos. Psicologia Ciência e Profissão, v.26, n.2, pp. 222-245, 2006. DOI: https://doi.org/10.1590/S1414-98932006000200006.

BRASIL. Base Nacional Comum Curricular (BNCC). Educação é a Base. Brasília, MEC/CONSED/UNDIME, 2017.

BRASIL. Ministério da Educação. Resolução CNE/CP n. 2, de 20 de dezembro de 2019. Define as Diretrizes Curriculares Nacionais para a Formação Inicial de Professores para a Educação Básica e institui a Base Nacional Comum para a Formação Inicial de Professores da Educação Básica (BNC-Formação). Diário Oficial [da] República Federativa do Brasil, Brasília-DF, 20 dez. 2019.

BARBIER, R. A pesquisa-ação. Brasília: Plano, 2002.

DESGAGNÉ, S. O conceito de pesquisa colaborativa: a idéia de uma aproximação entre pesquisadores universitários e professores práticos. Revista Educação em Questão, Natal, v. 29, n. 15, p. 7-35, maio/ago. 2007.

FRANCO, M. A. S. Pedagogia da pesquisa-ação. Educação e Pesquisa, São Paulo, v. 31, n. 3, p. 483-502, set./dez. 2005.

FREIRE, P. Pedagogia da autonomia: saberes necessários à prática educativa. Rio de Janeiro: Paz e Terra, 2011.

GARCIA, C. M. Formação de Professores: para uma mudança educativa. 1999.

IBIAPINA, I. M. L. de M. Pesquisa colaborativa: investigação, formação e produção de conhecimentos. Brasília: Líber Livro Editora, 2008.

JORDÃO, R. dos S. A Pesquisa-ação na Formação Inicial de Professores: elementos para a reflexão. FEUSP. GT: Formação de Professores/n.o8- Agência Financiadora: FAPESP. (2010). Acesso em: 17 out. 2016.

KINCHELOE, J. A formação do professor como compromisso político: mapeando o pós-moderno. Porto Alegre: Artes Médicas. 1997.

LEITE, S. A. S. A afetividade como objeto de pesquisa. In: BORUCHVITCH, E.; AZZI, R. G.; SOLIGO, A. (Org.) Temas em Psicologia Educacional: contribuições para a formação de professores. Campinas: Mercado das Letras, 2017. 
LEWIN, K. Action research and minority problems. Journal of Social Issues, n. 2, p. 34-36, 1946.

MAGAlHÃES, S. M. O.; SOUZA, R. C. C. R. de. A Questão do Método e da Metodologia: uma análise da produção acadêmica sobre professores(as) da Região Centro-Oeste/Brasil. Educ. Real., Porto Alegre, v. 37, n. 2, p. 669-693, maio/ago. 2012.

MARX, K. Manuscritos econômico-filosóficos. Trad. Jesus Ranieri. São Paulo: Boitempo, 2004.

MELO, G. F. Pedagogia Universitária: socialização e profissionalização de docentes principiantes na Educação Superior. Relatório de Pós-doutorado em Educação. Faculdade de Educação. Universidade de São Paulo. São Paulo, 2018.

MELO, G. F.; NAVES, M. L. P. Desenvolvimento profissional de professores universitários: reflexões a partir de experiências formativas. Educação e Sociedade. Revista do Programa de Pós-Graduação em Educação da UFPI, Teresina. 2014.

NAVES, F. F. Sentidos construidos por um educador popular acerca de sua prática com adolescentes: uma análise sócio-histórica. Dissertação (Mestrado) - Psicologia da Educação, Pontifícia Universidade Católica de São Paulo, 2011.

PEDRO, L. G. Como se fora brincadeira de roda - o grupo colaborativo como mediador do desenvolvimento docente. Tese de Doutorado. Faculdade de Educação, Universidade Federal de Uberlândia, Uberlândia, 2019.

PIMENTA, S. G. Pesquisa-ação crítico-colaborativa: construindo seu significado a partir de experiências com a formação docente. Educação e Pesquisa, São Paulo, v. 31, n. 3, p. 521-539, set./dez. 2005.

SACRISTÁN, G. J. Tendências investigativas na formação de professores. In: PIMENTA, S. G. (org.). Professor Reflexivo no Brasil: gênese e crítica de um conceito. $4^{a}$ Ed. São Paulo: Cortez, 2006.

SILVA, L. S.; CAMPOS, V. T. B. Saberes necessários à docência na educação superior na perspectiva da educação para todos/as. Revista de Educação Popular, p. 192-213, 29 set. 2021

THIOLLENT. M. Metodologia da pesquisa-ação. 12 ed. São Paulo: Cortez, 2003.

VIGOTSKI, L. S. A formação social da mente. São Paulo: Martins Fontes, 2000. 